\title{
Mapping an innovation ecosystem using network clustering and community identification: a multi-layered framework
}

\author{
Guannan $\mathrm{Xu}^{1} \cdot$ Weijie $\mathrm{Hu}^{1} \cdot$ Yuanyuan Qiao $^{2} \cdot$ Yuan Zhou $^{3}$ (D)
}

Received: 6 November 2019 / Published online: 8 June 2020

(c) The Author(s) 2020

\begin{abstract}
The existing literature on innovation ecosystem overlooks the differences between knowledge ecosystems and business ecosystems, and mostly focuses on a single-layer analysis of the ecosystem. Also, ecosystem mapping studies involve either whole-network analysis at the macro-level or ego-network analysis at the micro-level, while few studies have investigated network community analysis at the meso-level. Therefore, this paper proposes a framework of Multi-layered Innovation Ecosystem Mapping (MIEM) to explore both knowledge and business ecosystems, thereby extending the analysis to the network communities. Based on multi-source heterogeneous data and machine learning, MIEM includes four steps in conducting the analysis: define the research scope and collect data; construct whole networks; identify communities; and recognize strategic roles. In particular, Newman topological clustering is adopted to identify network communities, and a strategicrole matrix is used to analyze the roles in a community. Based on this framework, a case study of numerical-control machine tool ecosystem mapping is conducted using patents and value-added tax invoice data.
\end{abstract}

Keywords Innovation ecosystem · Machine learning - Network community identification · Multi-source heterogeneous data $\cdot$ Topological clustering $\cdot$ Multi-layered framework

\section{Introduction}

Innovation ecosystems are attracting increasing attention from both academics and practitioners. With the prevalence of open innovation, innovations are generated through complex and dynamic ecosystems that include diversified players (Frenkel and Maital 2014). Mapping an ecosystem can help to identify the components and the relationships amongst

Yuan Zhou

zhou_yuan@mail.tsinghua.edu.cn

1 School of Economics and Management, Beijing University of Posts and Telecommunications, Beijing 100876, People's Republic of China

2 School of Information and Communication Engineering, Beijing University of Posts and Telecommunications, Beijing 100876, People's Republic of China

3 School of Public Policy and Management, Tsinghua University, Beijing 100084, People's Republic of China 
the players, provide a holistic view of the system, examine the behavior pattern and impact mechanism, as well as monitor its evolutionary trends (Battistella et al. 2013; Xu et al. 2018). Along with the development of innovation ecosystem theories and mapping tools and methodologies, recent ecosystem mapping research has shown the following trends.

One the one hand, the mapping of innovation ecosystem needs to be expanded from a single-layer analysis to multi-layer analysis. An innovation ecosystem comprises two distinct subecosystems: the knowledge ecosystem and the business ecosystem (Clarysse et al. 2014; Oh et al. 2016). Knowledge creation in the knowledge ecosystem and value capture in the business ecosystem should both be emphasized when examining innovation ecosystems. The success factors that lead to knowledge ecosystems and business ecosystems could be different, and business ecosystems might not be the automatic consequence of setting up a knowledge ecosystem (Clarysse et al. 2014). However, most research on innovation ecosystems has focused on a single layer of the ecosystem, regardless of the heterogeneities and connections between the knowledge ecosystem and the business ecosystem (Xu et al. 2018). Along with the development of data science, abundant data from different sources can be used to profile innovation ecosystems, such as literature-based data (Shibata et al. 2008; Binz et al. 2014; Xu et al. 2018; Wang et al. 2018; Skute et al. 2019); patent data (Kim et al. 2014; Lee and Kim, 2017; Ardito et al. 2018; Zhou et al. 2016; Xu et al. 2018); and business data (Basole, 2009, 2016). Thus, the investigation of a multi-layered innovation ecosystem, which bridges the divide between the knowledge and business ecosystems, represents an avenue of needed research.

On the other hand, the mapping of innovation ecosystem needs more exploration from the meso-perspective of inter-organizational networks. Examining the innovation ecosystem with inter-organizational networks can help us to understand the complicated dynamic relationship between actors as well as provide a landscape of an innovation system (Shipilov and Gawer 2020). Existing research has either focused on whole-network analysis at the macro-level or probed into an individual firm's ego-network analysis at the micro-level. The whole-network perspective emphasizes the impacts of the macro environment (Schilling and Phelps 2007), while the ego-network perspective emphasizes the effects of focal firms' ties (Zaheer and Bell 2005; Ahuja 2000). Both perspectives risk an incomplete picture of an innovation ecosystem because they do not consider the network communities that account for the ecosystem's sub-environment. Innovation communities, also addressed as innovation clusters, can play an important role in innovation systems (Bell 2005; Porter 1998; Pouder and John 1996). Like biocoenosis in a natural ecosystem, innovation communities are of great significance to the evolution of an innovation ecosystem. The network community perspective provides a meso view of an ecosystem, which bridges the macrolevel and micro-level analyses. Therefore, mapping an innovation ecosystem with community identification at the meso-level deserves further research.

In addition, there has been an unprecedented development of big data as well as machine learning techniques (Liu et al. 2019), which provides novel methods for mapping the innovation ecosystem and analyzing innovation communities. Specifically, topological clustering is a promising method for network community identification. Unlike traditional clustering based on similarities in firms' attribute data, topological clustering can process network data and divide a large network into multiple clusters according to the aggregation degree of nodes in the network (Newman 2004; Sytch and Tatarynowicz 2014). This paper explores the application of topology clustering to identify innovation communities in an innovation ecosystem.

This paper aims to investigate the multi-layered innovation ecosystem using network clustering and community identification, in order to address the following questions: (1) What is the holistic view of an innovation ecosystem that enables knowledge and business value creation and capture? (2) What are the critical communities in an innovation 
ecosystem? (3) What are the strategic roles of firms in the critical communities that constitute the multi-layered innovation ecosystem? This paper proposes a framework for multilayered innovation ecosystem mapping, which provides a holistic view that help to inspect and promote open innovation synergies between knowledge and business, as well as probe into the innovation communities at meso-level.

The remainder of this paper is organized as follows. The second section discusses the existing literature on innovation ecosystems and its mapping approaches. The third section presents a methodology for mapping a multi-layered innovation ecosystem with machine learning. The fourth section conducts a case study to mapping the innovation ecosystem of the computer numerical control (CNC) machine tool industry in Ningbo, China. The final section concludes and discusses limitations and future research suggestions.

\section{Theoretical background}

\section{Innovation ecosystem: bridging the knowledge and business ecosystems}

An innovation ecosystem is defined as "the complex relationships that are formed between actors or entities whose functional goal is to enable technology development and innovation" (Jackson 2011). It should be noted that an innovation ecosystem comprises two distinct but largely separated economies: the research economy and the commercial economy (Oh et al. 2016). The former is driven by fundamental research, which can be recognized as the knowledge ecosystem. It aims to create scientific or technological knowledge for firms, universities and research institutes. The latter is driven by the marketplace, which can be recognized as the business ecosystem. It aims to create market value in connected networks of organizations where firms can gain competitive advantage through interactions with other players (Moore 1993). Knowledge and business ecosystems are distinct yet interacted. The knowledge ecosystems can provide scientific and technological support to firms for better delivery of business value, and the business ecosystem can provide value propositions to knowledge creators through the feedbacks of demand. The tension and linkage between knowledge ecosystems and business ecosystems may be the drivers of innovation ecosystem evolution (Oh et al. 2016). Thus, understanding both knowledge and business ecosystems, as well as their interactions or dynamics, may help to better assess an innovation ecosystem (Xu et al. 2018).

Some recent literature has explored the coexistence of knowledge ecosystems and business ecosystems. For example, Clarysse et al. (2014) found a disconnect between the development of knowledge ecosystems and business ecosystems through an empirical study in Belgium. Furthermore, knowledge ecosystem can also be divided into science ecosystem and technology ecosystem according to the heterogeneities of knowledge characteristics. For instance Xu et al. (2018), proposed a framework to analyze innovation ecosystems across science, technology and business layers, and conducted a case study in the 3D printing industry. However, relevant research remains sparse, and analysis of the innovation ecosystem needs to be expanded from a single layer to multiple layers that bridge the research economy and the commercial economy.

As a result, most ecosystem mapping research also focuses on a single layer of an innovation ecosystem, regardless of the differences between knowledge ecosystems and business ecosystems (Xu et al. 2018). A holistic framework is needed to map the multi-layered innovation ecosystem and bridge the knowledge and business ecosystems. 


\section{Approaches of ecosystem mapping}

Literature proposes several approaches to map and analyze ecosystems, such as the qualitative mapping based on interviews (Li 2009; Isckia 2009; Rong et al. 2015), and quantitative mapping based on surveys or objective data (Clarysse et al. 2014; Battistella et al. 2013; Basole, 2009; Salavisa et al. 2012). Early work on ecosystem mapping focused on qualitative case studies, such as describing the evolution of an ecosystem (Isckia 2009; Li 2009) and investigating it through context, cooperation, construct, configuration, capability, and change (Rong et al. 2015). In recent years, there has been an increasing amount of literature on innovation ecosystem mapping with social network analysis. For example, some scholars use interview data and web data to investigate the network structure of an innovation ecosystem (Panetti et al. 2019), whereas other scholars use in-depth interviews complemented by documentary data to explore firms' networking behaviours in an innovation ecosystem (Salavisa et al. 2012). Adding to this, scholars tend to use objective data, such as literaturebased data (Binz et al. 2014; Xu et al. 2018; Skute et al. 2019; Shibata et al. 2008), patent data (Ardito et al. 2018; Lee and Kim 2017; Xu et al. 2018; Kim et al. 2014), and business data (Basole 2016, 2009), for network construction. Mapping innovation ecosystem with multi-source heterogeneous data and novel methods is an emerging research trend.

Another important research trend is to enrich ecosystem scholarship with systematic applications of network analytic tools(Shipilov and Gawer 2020). Relevant research has applied two complementary perspectives: whole-network perspective (also called the global network perspective) at the macro level, and the ego-network perspective at the micro-level. However, few studies have investigated the network community perspective at the meso level.

On the one hand, the first perspective conducts a whole-network analysis of a regional system or a sectoral system, which increases the understanding of the overall structure of the ecosystems. For example, some researchers used network indicators to describe the connection of entities and the information flow among key players in a specific region or sector (Clarysse et al. 2014; Battistella et al. 2013); others used an average path length and a clustering coefficient to measure the small-world characteristics of the whole network (Panetti et al. 2019; Basole 2016). The macro-level analysis from the whole-network perspective pays attention to inter-firm interactions through a broader social space, including the overall structure of firms and their ties within the industry (Schilling and Phelps 2007; $\mathrm{Xu}$ et al. 2018). Such research provides an overview of an innovation ecosystem, emphasizing the impacts of macro environments throughout an industry. On the other hand, the second perspective conducts firm-level analysis to explore firms' connections and positions in an ego-network. For example, centrality (such as degree, betweenness and closeness centrality) is used to describe a firm's position in the network (Basole 2009; Salavisa et al. 2012), and a structural hole is used to measure a firm's power in the network (Ahuja 2000). The micro-level analysis from an ego-network perspective suggests that a firm's activities and performances are critically shaped by the firm's ties to its partners and the partners' ties among themselves (Ahuja 2000; Zaheer et al. 2010). Such research provides a close-up of key firms, emphasizing the roles of an individual firm in an innovation ecosystem. However, both perspectives cannot take a complete picture of an innovation ecosystem due to ignoring the ecosystem's sub-environment. Thus, further exploration of meso-level analysis from a network community perspective is required.

A network community perspective provides a meso view of an ecosystem that bridges macro-level and micro-level analysis. Network communities, prevalent in a range of 
inter-organizational systems, are dense, non-overlapping structural groups, within which actors are connected more to each other than to actors outside their group (Sytch and Tatarynowicz 2014). Network communities that demarcate heterogeneous activities and strategic positions in inter-organizational systems can significantly impact firms' innovation activities (Sytch and Tatarynowicz 2014). Thus, communities can be recognized as important analysis units, which also promotes the interactive evolution of the innovation ecosystem.

Clustering is considered as the most important unsupervised machine learning method for community identification (Ibáñez et al. 2013). At present, there are several clustering methods applied to community detection (Kim et al. 2008), such as the hierarchical clustering method (Maimon and Rokach 2010), the self-organizing feature maps (SOFM) clustering method (Kohonen 1982), and the spectral method and Kernighan-Lin algorithm (Kernighan and Lin 1970). Traditional clustering is usually based on similarities in firms' attribute data or through sociometric techniques based on a high density of intragroup rivalry relations (Porac et al. 1995; Fiegenbaum and Thomas 1990). For example, some research has used K-means clustering to identify technology communities(Kim et al. 2014), whereas other research has used partitional clustering, hierarchical clustering, and probabilistic clustering to identify clusters of research activities (Ibáñez et al. 2013).

Newman Topological clustering, one of the most robust methods of network community identification (Danon et al. 2005), identifies communities by assessing the difference in community structure between the actual network and a random network of the same size and degree distribution (Sytch and Tatarynowicz 2014). Compared to some traditional methods of community detection, it offers a statistically validated partitioning of the network, while not requiring any a priori assumptions (e.g., the number of communities). Therefore, Newman topological clustering is especially suitable for the community identification in an innovation ecosystem, where it is difficult to provide ex ante information such as the number of communities (Sytch and Tatarynowicz 2014).

\section{Framework of multi-layered innovation ecosystem mapping (MIEM)}

In order to provide a holistic view of an innovation ecosystem bridging knowledge and business, as well as to shed light on network communities at the meso level, this paper constructs a framework of MIEM for mapping a multi-layered innovation ecosystem (see Fig. 1).

The research scope of an innovation ecosystem in MIEM is defined as multi-layered networks that connect multiple innovation actors in order to co-create knowledge and business value in a specific industry. (1) It consists of two complementary and synergistic sub-ecosystems: knowledge and business. The former generates knowledge that advances technological development, while the latter develops products and services and realizes business value propositions. (2) An innovation ecosystem comprises a range of communities (i.e., clusters or cliques), within which actors interplay closely for synergetic and collaborative value creation and capture. (3) Like species in a biocoenosis in a natural ecosystem, there are also different roles of players in a community that symbiotically contribute to the evolution of an innovation ecosystem.

In this framework, multi-source heterogeneous data can be used to explore both knowledge and business (sub-)ecosystems in an innovation ecosystem. Based on machine learning and social network analysis, Newman topological clustering is applied to identify network communities, which helps to analyze homogeneity and heterogeneity within and between communities in the ecosystem. 

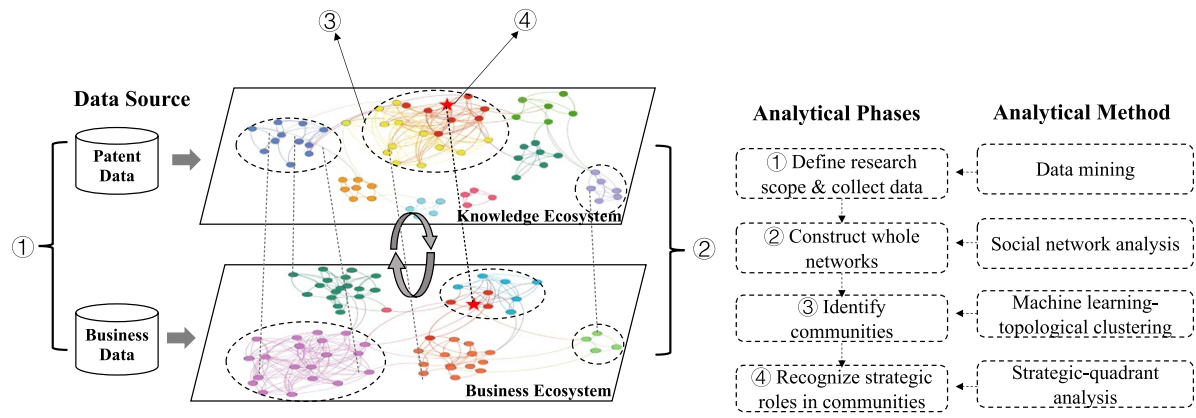

Fig. 1 Framework of a multi-layered innovation ecosystem mapping

There are four steps to conduct the analysis: (1) define research scope and collect data; (2) construct a whole network of a multi-layered innovation ecosystem; (3) identify communities in a multi-layered innovation ecosystem; and (4) recognize strategic roles in communities.

\section{Define research scope and collect data}

\section{Ecosystem boundaries and elements}

First, we need to define the boundaries of the innovation ecosystem, including its regional and sectoral boundary. The former can be global, national or local, while the latter considers the scope of the industry, or some specific value functions along an industrial value chain. Understanding and identifying the value functions, enabling technologies, key products and services can help to define boundaries precisely.

Next, we need to identify players in the innovation ecosystem, such as firms, universities, research institutions, venture capitalists, and service agencies. In this research, we only focus on firms.

Then, we need to identify the relationships among players. Innovation ecosystem includes a series of complex relationships between players such as cooperation, competition, and complementation. Specifically, cooperation is essential to ensure the availability of components and to facilitate ecosystem emergence and value creation, and it is regarded as an important relationship for firms in an ecosystem (Hannah and Eisenhardt 2018; Adner 2017; Adner and Kapoor 2010). Therefore, in the framework of MIEM, we focus on the relationship of cooperation between players in a multi-layered innovation ecosystem.

\section{Data collection}

Collect data for multi-layered innovation ecosystem analysis based on the above elements.

Knowledge ecosystem, which generates scientific and technological knowledge, can be analyzed by using patent data and other science and technology-related data ( $\mathrm{Xu}$ et al. 2018). A patent database such as the Derwent World Patents Index (DWPI); the Derwent Patents Citation Index (DPCI), and the U.S. Patent and Trademark Office (USPTO) are often used (Zhou et al. 2020). Other data sources include official technology reports and literature databases such as Web of Science (Zhou et al. 2019b).

Business ecosystem, which creates and captures business value, can be analyzed by using product/service data or other market-related information (Xu et al. 2018). The data 
sources can include the value-added tax (VAT) invoice database, industrial reports, news, official websites, and annual reports.

\section{Construct whole networks of multi-layered innovation ecosystem}

\section{Whole network construction on each layer}

An ecosystem can be regarded as complex networks of players, representing nodes and relationships (Battistella et al. 2013). This step uses the data obtained from the previous step to construct the whole network for each layer, in order to provide an overview of a multi-layered innovation ecosystem.

In general, a knowledge ecosystem can be represented by patent/paper cooperation networks (Xu et al. 2018), R\&D cooperation networks (Clarysse et al. 2014), and R\&D alliance networks. A business ecosystem can be represented by product trading networks, product development collaboration networks (Xu et al. 2018), and business alliance networks.

In the case study of MIEM in this paper, a knowledge network is constructed based on co-patenting relationships, and a business ecosystem is constructed based on product transaction relationships. Indicators from social network analysis are useful for providing an overview of the whole network, such as network density, small world coefficient, average degree centrality, and weighted cluster coefficient.

\section{Identify linkages between layers}

This step is to identify linkages between layers for the assessment of the overall interplay between knowledge and business ecosystems. There are several methods to identify the linkages. Connecting the same players between layers is most direct and the simplest. If related data are available, we can also construct linkages between layers when a player in a knowledge ecosystem and a player in a business ecosystem collaborate on technology transfer. For industrial development, especially during the period of paradigm transformation, the linkage between the knowledge and business ecosystem is vital (Kong et al. 2017; Zhou et al. 2019c).

\section{Identify communities in multi-layered innovation ecosystem}

\section{Identify communities on each layer}

This step identifies communities in an innovation ecosystem in order to conduct a mesolevel analysis. Network communities are typically identified based on dense patterns of collaborative interactions among firms (Sytch et al. 2012). In the case study of MIEM in this paper, communities are identified based on dense patterns of co-patenting in a knowledge ecosystem, and on dense patterns of product transaction in a business ecosystem.

This paper utilizes the Fast-Newman (FN) algorithm to conduct community identification. This topological clustering algorithm proposed by Newman is suitable for the analysis and processing of network data based on interaction structure, and can deal with large networks with relatively short calculation times (Shibata et al. 2008).

The FN algorithm does not need to specify the number of clusters as K-means clustering, but automatically divides the network into the optimal number of clusters according 
to the aggregation characteristics between nodes (Zhou et al. 2019a). The optimization strategy of the FN Newman clustering algorithm is to maximize the modularity $Q$ of the divided network, which is defined as follows:

$$
Q=\sum_{s}\left(e_{\mathrm{st}}-a_{s}^{2}\right)^{2}=\operatorname{Tr}(e)-\|e\|^{2}
$$

where $e_{\mathrm{st}}$ denotes the density value of the interconnected nodes between the cluster $s$ and the cluster $t, a_{s}=\sum_{t} e_{\mathrm{st}}, \operatorname{Tr}(e)$ denotes the sum of the density of edges within each cluster, and $\|e\|^{2}$ denotes the sum of the density of connections within each cluster when all connections are randomly generated. Then the algorithm is used to optimize $Q$ over all possible divisions to find the best structure of clusters. The larger the modularity, the better the network division results. At this point, there are dense network connections within each cluster and sparse network connections between the clusters. This analysis involves understanding the community structure of the overall innovation ecosystem (number, size and network indicators of communities) and aids in the understanding of the value sharing among communities (Newman 2004).

\section{Identify linkages between layers}

This step identifies the linkages between layers in order to assess the interplay of communities between knowledge and business ecosystems. In this paper, we connect the same players between layers. We also evaluate the similarity between communities from different layers according to the similarity of community members, which aids in understanding the interactions between knowledge and business ecosystems at the meso-level.

\section{Recognize strategic roles in communities}

This step recognizes players' strategic roles in communities. Like species in a biocoenosis in a natural ecosystem, there are also different roles of players in communities in an innovation ecosystem. The strategic roles of players can be explained by the strategic-quadrant analysis of the innovation community. Specifically, learning from Iansiti and Levien (2004), we classify the strategic roles in a community as keystone, dominator, niche player, and commodity player. Thus, we construct strategic-role matrices to recognize the strategic roles of players in communities within a layer and across layers (see Fig. 2).

\section{Strategic roles in communities within a layer}

As seen in Fig. 2a, we recognize the strategic roles in communities within a layer according to two dimensions: centrality and diversity in a community. On the one hand, we consider a firm's centrality of network position in a community. According to the Pareto principle (also known as the $80 / 20$ rule), ${ }^{1}$ the bottom $80 \%$ of players can be regarded as commodity players, while the top $20 \%$ have relatively important roles in a community. On the other hand, we further take into account a firm's diversity along the value chain for the top $20 \%$ of players. If a firm concentrates on a single function of the value chain, it can be

\footnotetext{
1 The Pareto principle states that, for many events, roughly $80 \%$ of the effects come from $20 \%$ of the causes.
} 


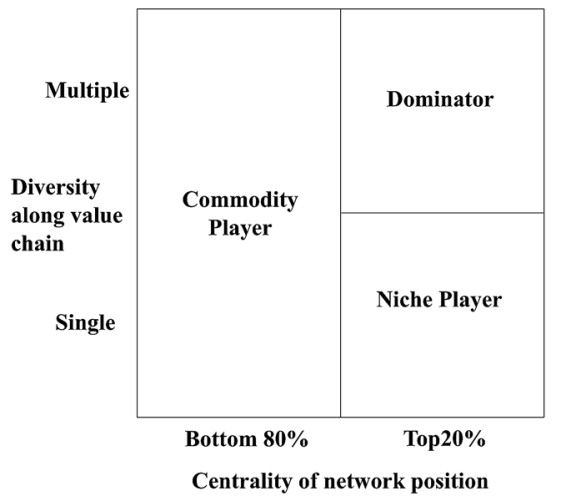

(a)

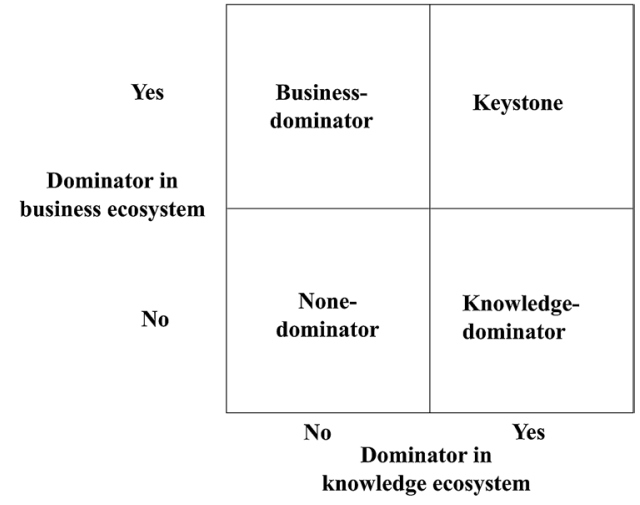

(b)

Fig.2 Strategic-role matrix. a Within-layer analysis; b Cross-layer analysis

regarded as a niche player. If a player has diversified functions along the value chain, it is a dominator.

Thus, there are three types of roles in communities within a layer: dominator, niche player, and commodity player. Similar to the definition from Iansiti and Levien (2004), dominators have critical positions in networks and control the value creation and capture in a community; niche players focus on a narrowly and clearly defined technology or business segment, and develop a specialized function that contributes to the functioning of their community; commodity players are in marginal positions in networks and create less value to sustain the community.

\section{Strategic roles in communities across layers}

After identifying the strategic roles in communities within a layer, we further analyze players' strategic roles across layers, especially for those dominators either in a knowledge ecosystem or a business ecosystem.

As shown in Fig. 2b, depending on whether a player is a dominator in a knowledge ecosystem or whether it is a dominator in a business ecosystem, four strategic-role quadrants are constructed: business-dominator, knowledge-dominator, none-dominator, and keystone. In particular, if a player is a dominator in both knowledge and business ecosystems, it is a keystone. Keystones play a crucial role in an innovation ecosystem, and can create a platform and improve the health of the ecosystem as a whole (Iansiti and Levien 2004).

Hence, with community analysis and strategic role analysis of the multi-layered innovation ecosystem, we can have an in-depth and meso-view of the ecosystem, which complements the macro and micro-level analysis.

\section{A case study of MIEM}

Based on the MIEM framework, we conducted a case study of the innovation ecosystem of the CNC machine tool industry in Ningbo, China. The CNC machine tool industry is a strategic industry for upgrading manufacturing processes in the paradigm shift of digitalization 
Fig. 3 Value chain of the CNC machine tool industry

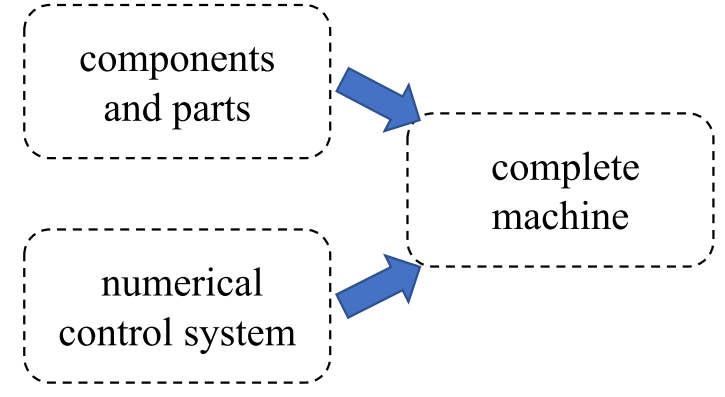

transformation, and it is one of the critical sectors in the "Made in China 2025" program. Ningbo is a first pilot demonstration city of "Made in China 2025," with 59 pilot projects for intelligent manufacturing technology and equipment. The innovation ecosystem of Ningbo's CNC machine tool industry has been continuously developing and exemplifies China's rapidly growing industrial innovation ecosystem.

\section{Define research scope and collect data}

\section{Ecosystem boundaries and elements}

First, we define the boundaries of the ecosystem and identify the value functions along the value chain. This study focuses on Ningbo's CNC machine tool innovation ecosystem. The value chain of the CNC machine tool industry is divided into three segments: components and parts, numerical control system and complete machines (see Fig. 3). For the business ecosystem, we involved all the firms along the industrial value chain that have CNC machine tool-related product transactions in Ningbo. For the knowledge ecosystem, as technological knowledge and industrial development are more closely linked, we only focused on the technological knowledge generation in this case study, which can be analyzed by using patent data. Thus, we involved entities that have patent applications in fields related to CNC machine tools. To sum up, we examined the relationships of product transactions in a business ecosystem and patent cooperation in a knowledge ecosystem.

\section{Data collection}

This study uses patent data and product transaction data to analyze the innovation ecosystem. We formulated the data collection strategy with experts in mechanical engineering from the Chinese Academy of China; the China Academy of Machinery Science and Technology; and the Wuhan Huazhong Numerical Control Co. The data collection process is shown in Fig. 4.

The data of the business ecosystem was obtained from the Enterprise VAT Invoice Database of Ningbo. This database provides the invoice information of each product transaction between 2015 and 2017, such as buyer, seller, product name, and its commodity code. We screened all CNC machine tool-related invoice data by commodity codes (see "Appendix 1"), including components and parts (commodity codes: 1090109, 1090119-1090121, and 1090123-1090125), NC system (commodity code: 109010804), and complete machine (commodity codes: 1090105-1090107, and 109010801-109010803). Thus, we retrieved 


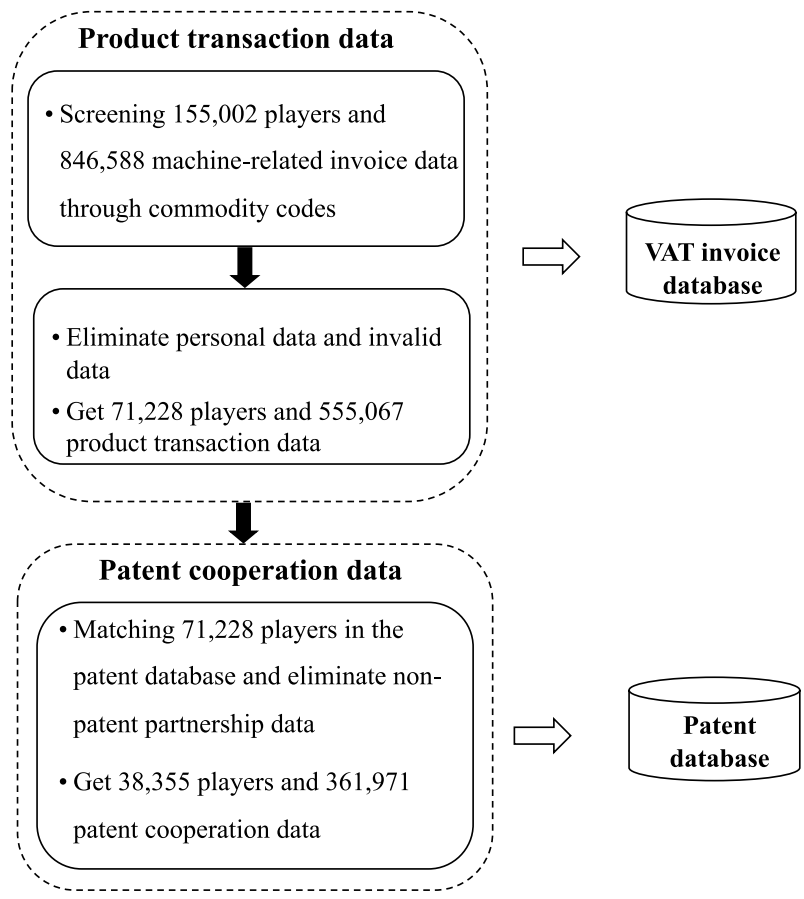

Fig. 4 Data collection process

846,588 CNC machine tool-related transactions and 155,002 players. After eliminating personal data, 555,067 transactions and 71,228 entities were retrieved from the business ecosystem of Ningbo's CNC machine tool industry. Specifically, 38,157 entities acted as sellers in these transactions, while 33,071 entities acted only as buyers.

Data of the knowledge ecosystem was obtained from the patent database of the China Intellectual Property Office. We searched for the above 71,228 machine tool-related entities in the patent database and retrieved all their related patents. After data cleaning, 38,355 players with patent application and patent collaboration were matched, and a total of 361,971 patent collaboration data until the year 2017 were retrieved. Furthermore, we used a 4-digit IPC code (see "Appendix 2") to identify the segments along the value chain of CNC machine tool industry: components and parts (IPC code: B23Q), NC system (IPC code: G05B), and complete machine (IPC code: B23B, B23C, B23D, B23F, B23G, B23H, $\mathrm{B} 23 \mathrm{~K}$ and $\mathrm{B} 23 \mathrm{P})$.

For the knowledge ecosystem, we used the 4-digit IPC Code to identify players in the three segments along the value chain of the $\mathrm{CNC}$ machine tool industry: components and parts (B23Q); NC system (G05B); and complete machine (B23B, B23C, B23D, B23F, B23G, B23H, B23K and B23P). As seen in Fig. 5, 97.63\% of the entities have patent applications in the segment of components and parts; $4.34 \%$ of the entities have patent applications in NC systems; and 32.88\% of the entities have patent applications in complete machines.

For the business ecosystem, we further focused on the sellers in the transactions, and identified suppliers in the three segments along the value chain of CNC machine tool industry by commodity codes (see "Appendix 1"). Among the suppliers, 83.06\% of the players supply components and parts; $2.90 \%$ of the players supply NC systems; and $20.61 \%$ of the players supply complete machines (see Fig. 5). 


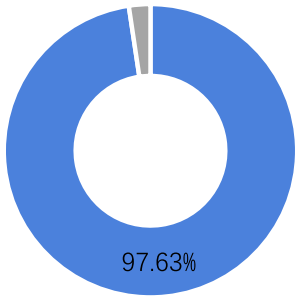

- Components and parts

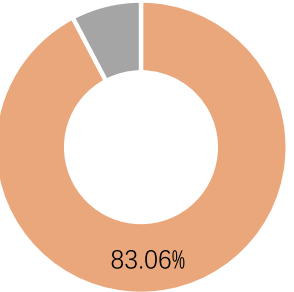

- Components and parts

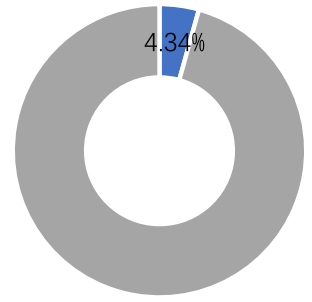

- Numerical control system

\section{Knowledge ecosystem}

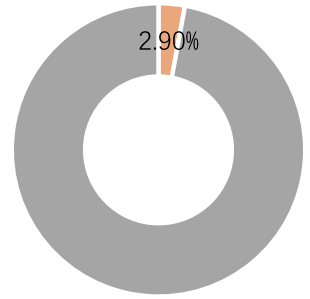

- Numerical control system

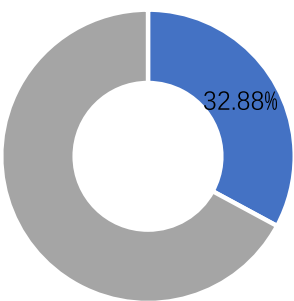

- Complete machine

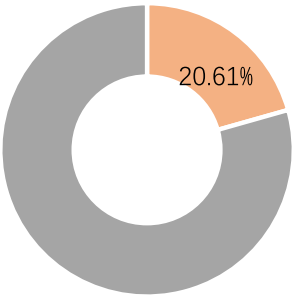

- Complete machine

\section{Business ecosystem}

Fig. 5 Distribution of entities along the value chain of Ningbo's CNC machine tool industry

\section{Construct whole networks of multi-layered innovation ecosystem}

\section{Whole network construction on each layer}

We constructed the whole networks on each layer, with players as nodes. For the knowledge ecosystem, we constructed the whole network based on co-patenting relationships as well as identified a linkage between players if they had any collaboration on patent applications. For the business ecosystem, we constructed the whole network based on product transaction relationships, and identified a linkage between players if they had any transactions. Next, we used the NetworkX function in Python to visualize the innovation ecosystem of Ningbo's CNC machine tool industry (see Fig. 6).

The network density of the knowledge ecosystem is $0.0091 \%$, while the network density of the business ecosystem is $0.0029 \%$. It indicates that the business network is sparser than the knowledge network. The network clustering coefficient of the knowledge ecosystem is $23.65 \%$, while the network clustering coefficient of the business ecosystem is $1.13 \%$. It implies that the community structure of the knowledge network is more potent than that of the business network. From this finding, we argue that the knowledge ecosystem has a higher collaboration intensity and a greater level of interaction among community members than the business ecosystem. 


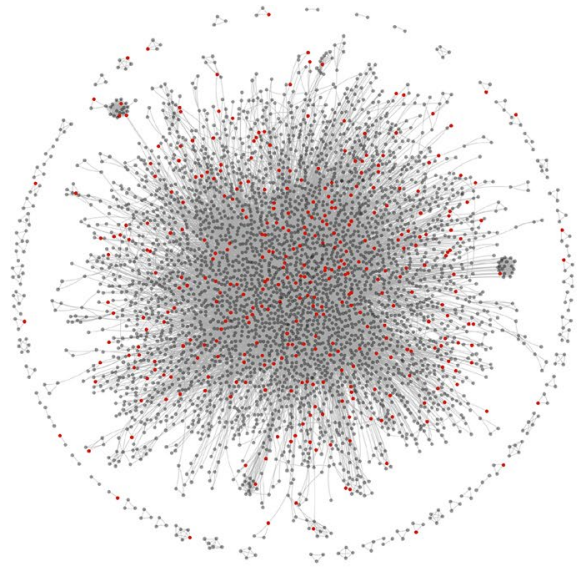

(a)

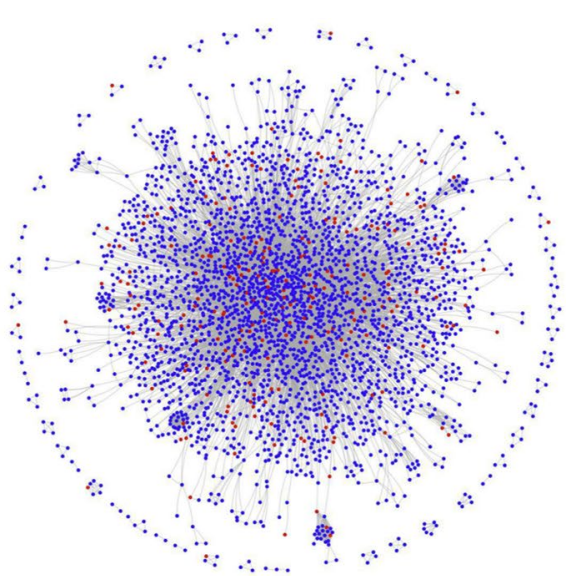

(b)

Fig. 6 Whole network construction on each layer. a Knowledge ecosystem; b Business ecosystem

\section{Identify linkages between layers}

To conduct a cross-layer interplay analysis of the multi-layer innovation ecosystem, we used Pymnet, a free library in Python, to analyze the multi-layer whole networks in the innovation ecosystem. We identified a linkage between the players on different layers, if the player occurs in both knowledge and business ecosystems (see Fig. 7).

There were 4957 linkages identified between layers, which indicates that only a very small portion of the overall players have active roles in both knowledge and business ecosystems, while most players only focus on a single layer of knowledge or business.

\section{Identify communities in multi-layered innovation ecosystem}

\section{Identify communities on each layer}

We identified communities on each layer using the Newman topological clustering method. Knowledge ecosystems and business ecosystems were divided into separate communities. The algorithm proposed is based on the calculation of modularity $Q$. In this paper, we stopped running the algorithm when $Q$ reaches a maximum, because our purpose is to extract more relevant structures concerning the networks, and the community identification result in this circumstance is considered optimal.

Figure 8 provides an overview of the community identification results in knowledge and business ecosystems. We identified 80 communities among the 38,355 players in the knowledge ecosystem and 104 communities among the 71,228 players in the business ecosystem. It appears that communities in knowledge ecosystems are relatively smaller and more scattered, while communities in business ecosystems are relatively larger and more concentrated.

Tables 1 and 2 summarizes the characteristics of the top ten communities in knowledge and business ecosystems. The largest community in the knowledge ecosystem has 5062 players, while the largest in the business ecosystem has 16,045. 


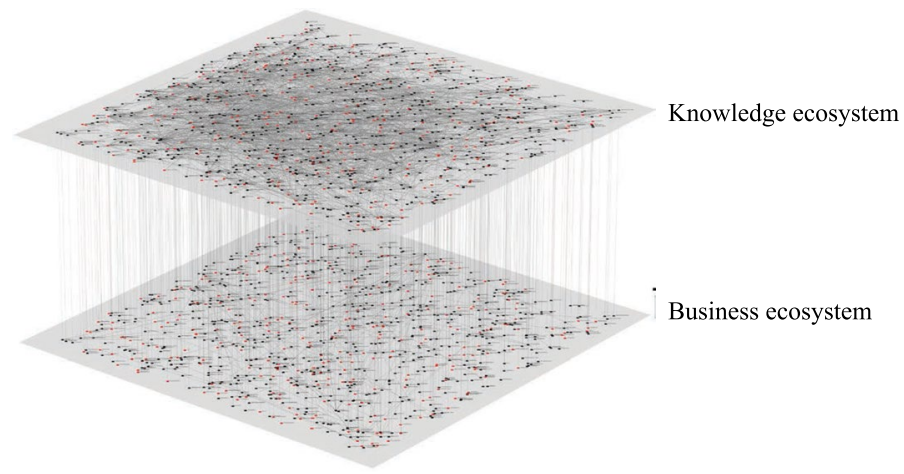

Fig. 7 Holistic view of multi-layered innovation ecosystem

(a)

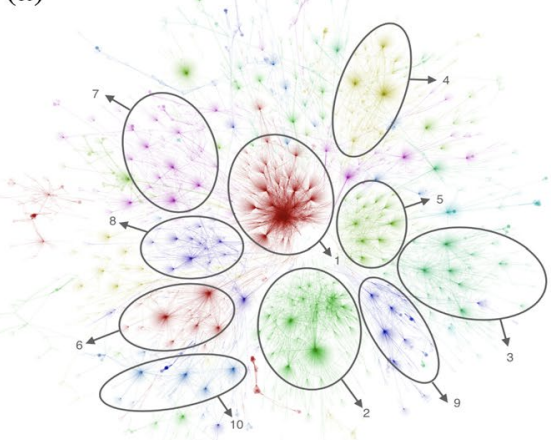

(b)

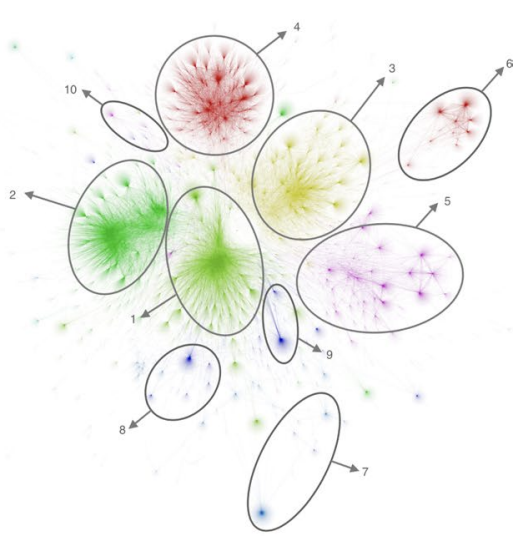

Fig. 8 Community identification on each layer. a Knowledge ecosystem; b Business ecosystem

As to the network indicators, the density of each community varies, and larger communities tend to have lower densities than smaller communities. We noticed that the average clustering coefficients of communities in the knowledge ecosystem are much higher than those in the business ecosystem. This implies that there is more frequent collaboration and knowledge sharing within a community in the knowledge ecosystem than that in the business ecosystem. Besides, the network centralization indicates the tendency of a single point to be more central than all other points in the network(Freeman 1979). The network degree centralization and betweenness centralization in knowledge communities are mostly at low and medium levels (ranging from 0.1219 to 0.6424 ), while the centralization in business communities varies widely (ranging from 0.0616 to 0.9635 ). This indicates that cooperation activities and controlling power are scattered within most knowledge communities, while they can be either evenly distributed or heavily concentrated in business communities. In this respect, business communities are more diversified than knowledge communities. 


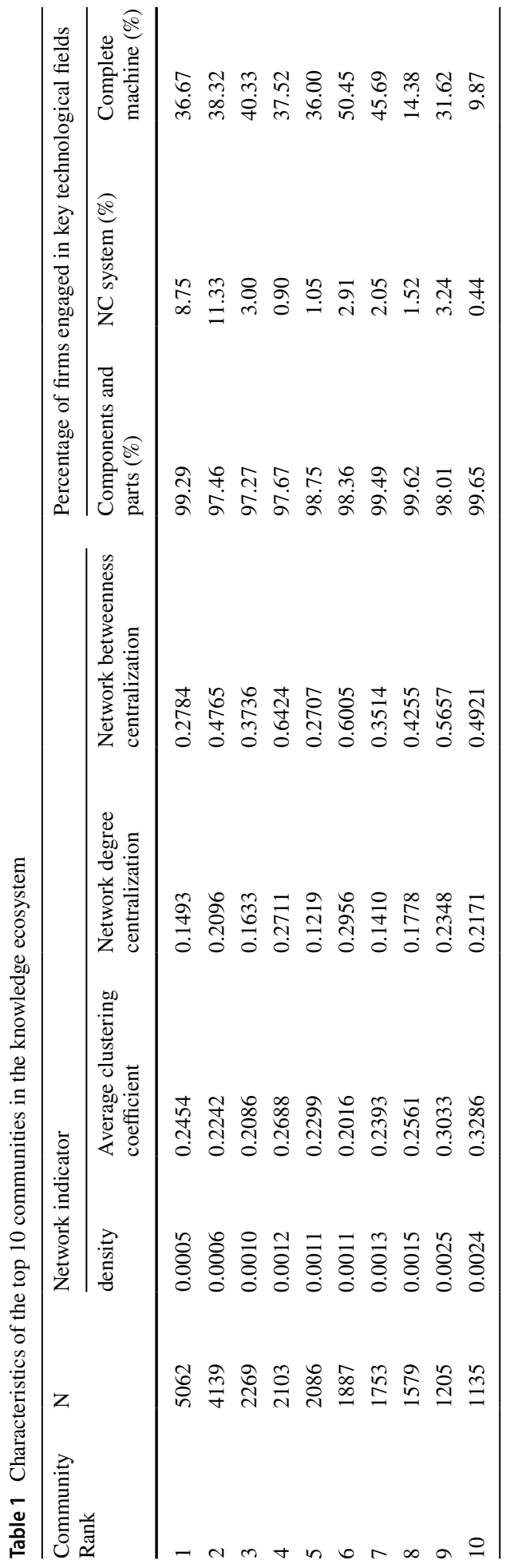




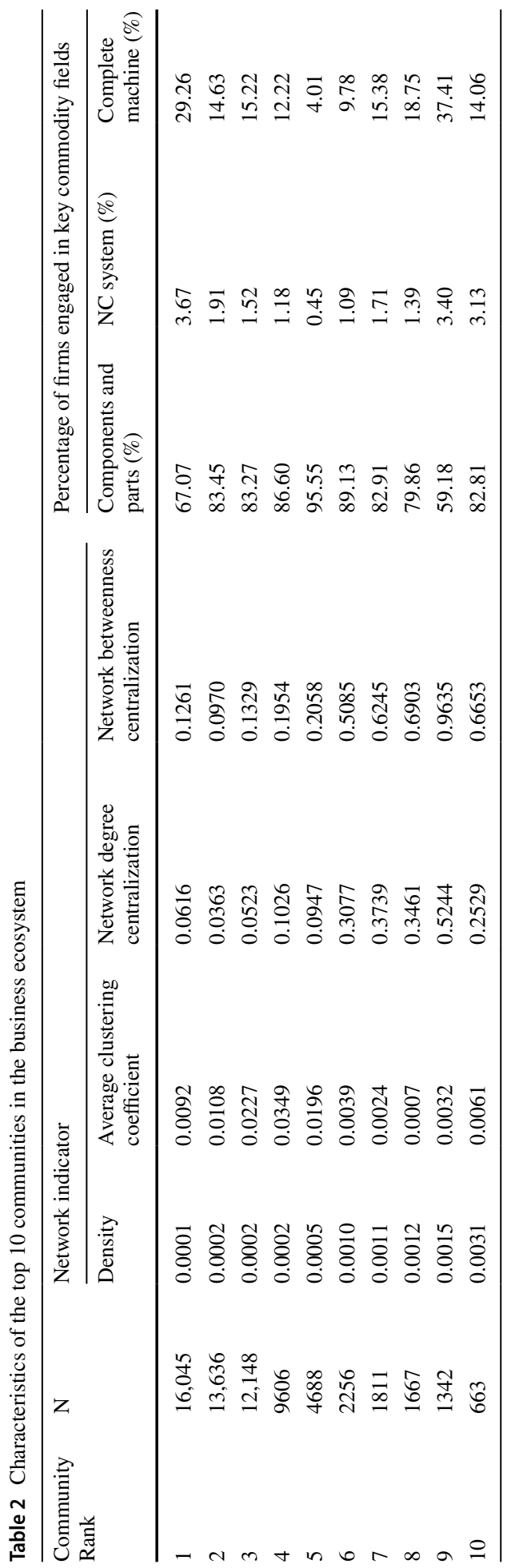




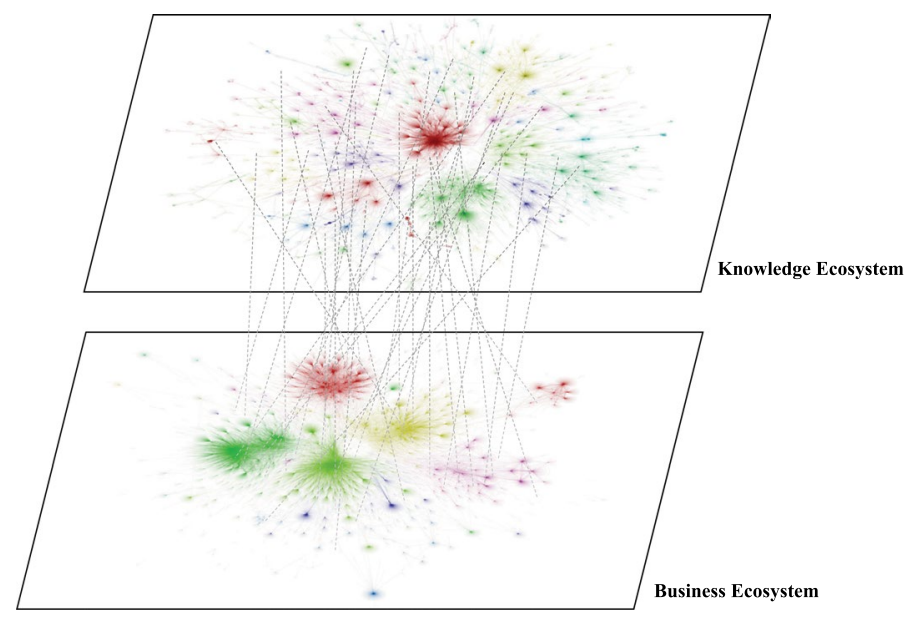

Fig. 9 Holistic view of community in multi-layered innovation ecosystem

As to the percentage of firms engaged in key fields, it appears that the communities in knowledge and business ecosystems have quite different distribution along the industrial value chain. In knowledge ecosystem, there are more than $97 \%$ firms that have patent applications in components and parts in all the top ten communities, while the percentage of firms with expertise in NC system ranges from $0.44 \%$ to $11.33 \%$, and the percentage of firms with expertise in complete machine ranges from $9.87 \%$ to $50.45 \%$. In business ecosystem, there are $59.18 \%$ to $95.55 \%$ firms that have transactions on components and parts in all the top ten communities, while only $0.45 \%$ to $3.67 \%$ firms sell NC systems, and $4.01 \%$ to $37.41 \%$ firms sell complete machines.

\section{Identify linkages between layers}

We also identified a linkage between the players on different layers if the player occurs in both knowledge and business ecosystems. We calculated the similarity between communities on different layers based on the percentage of overlapping players between the two communities (see Fig. 9).

The results indicate that the similarity between most communities on different layers is very low, which means that most companies have different partners in the research world and the commercial world. Even for the two most similar communities, only about $1 \%$ of the players overlap, which also aligns with the points of heterogeneities between knowledge and business ecosystems (Clarysse et al. 2014; Oh et al. 2016).

\section{Recognize strategic roles in communities}

\section{Strategic roles in communities within a layer}

In regard to the strategic roles in knowledge ecosystems, we used the degree centrality of a player in a community to measure the centrality of network position, and the IPC codes of a player's patent applications to judge its diversity along the three segments of the industrial value chain. Firms with patent applications in at least two segments were considered 


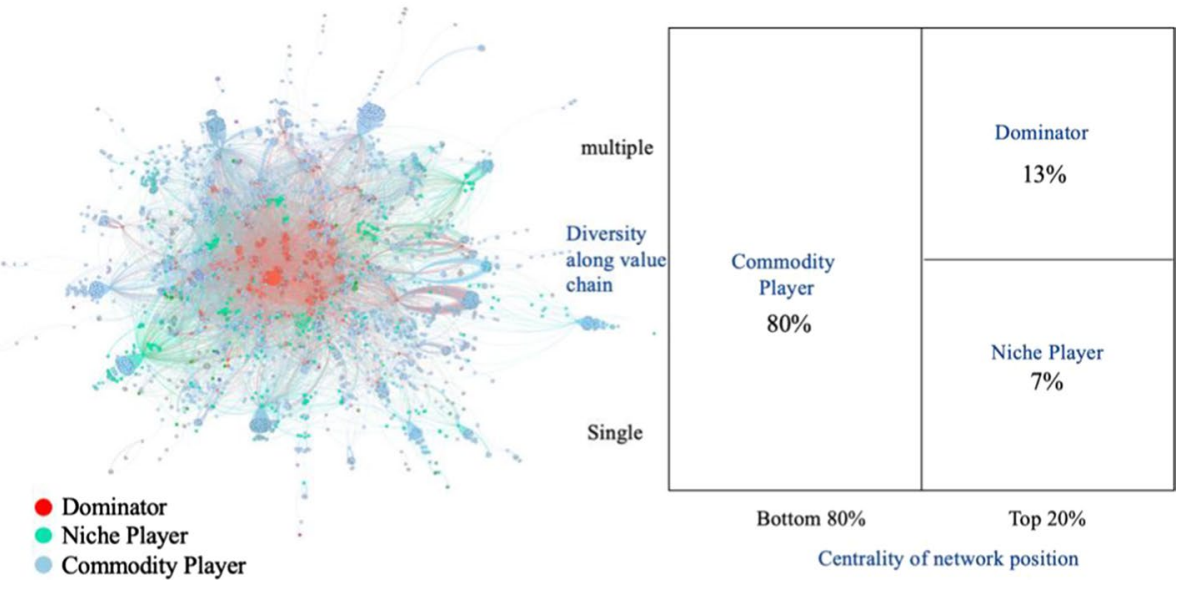

Fig. 10 Strategic roles in community of knowledge ecosystem

to have multiple functions along the value chain; firms with patent applications in only one segment were considered to have a single function along the value chain.

As shown in Fig. 10, we randomly selected a community as an example. According to within-layer analysis of the strategic-role matrix, we identified $80 \%$ of the players as commodity players, $13 \%$ of the players as dominators, and $7 \%$ of the players as niche players in the community.

Regarding the strategic roles in business ecosystems, we focused on the suppliers along the value chain. We also used the degree centrality of a player in a community to measure the centrality of network position, and the commodity codes to judge its diversity along the three segments of the industrial value chain. Similar to knowledge ecosystems, firms with products in at least two segments of the industrial value chain were considered to have multiple functions along the industry chain, whereas firms with products in only one segment of the value chain were considered to have a single function along the industry chain.

As shown in Fig. 11, we selected the community that had the highest similarity with the above-analyzed community as an example. We identified $80 \%$ of the players as commodity players, $2 \%$ as dominators, and $18 \%$ as niche players in the community.

By comparison, there is a larger proportion of dominators in knowledge ecosystems, while there are more niche players in business ecosystems.

\section{Strategic roles in communities across layers}

We further analyzed players' strategic roles across layers, especially for all the dominators within a layer (including 1205 dominators in knowledge ecosystems and 2874 dominators in business ecosystems). As shown in Fig. 12, among all the dominators in Ningbo's CNC machine tool industry, there were only five keystones identified, accounting for $0.005 \%$ of all players in the innovation ecosystem. To our surprise, there was only one Ningbo local company among the five keystones. This calls for the strategic development of local core firms in the innovation ecosystem of Ningbo's NC machine tool industry.

Furthermore, we take a close-up of the strategic roles in communities across layers (see Fig. 13). We select a community in the knowledge ecosystem, and examine the strategic roles of 210 knowledge-dominators in the business ecosystem. To our surprise, only two 


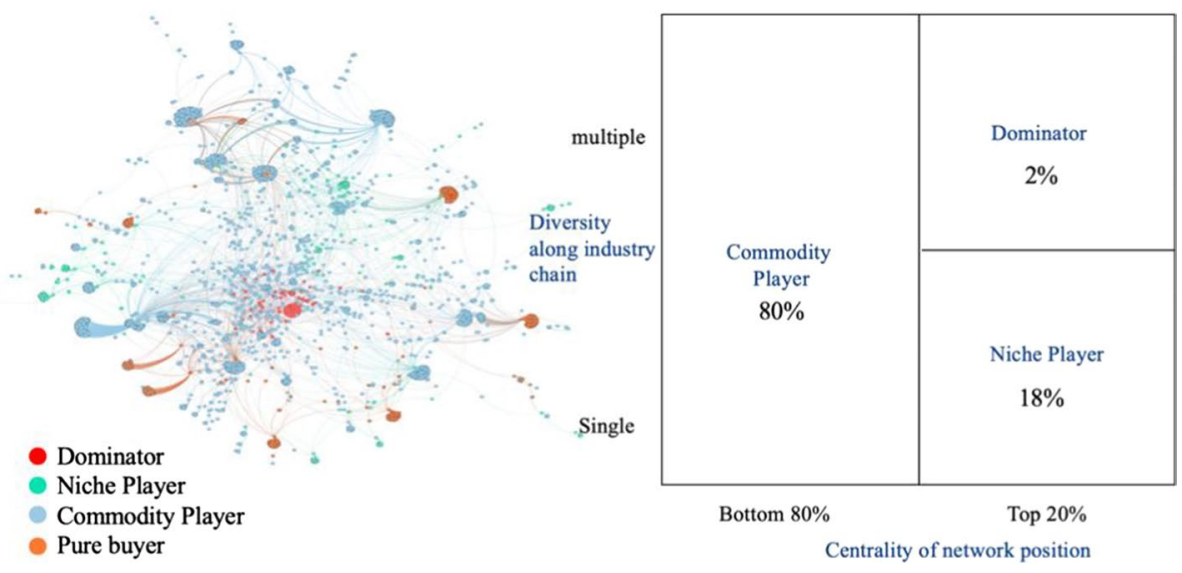

Fig.11 Strategic roles in community of business ecosystem
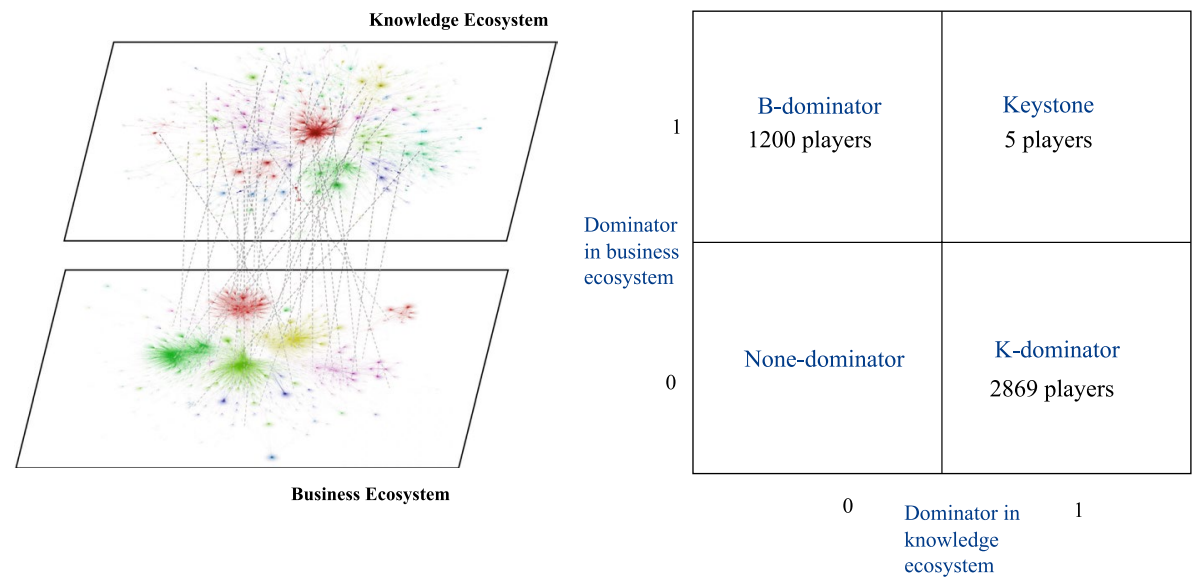

Fig.12 A snapshot of strategic roles in communities of innovation ecosystem

dominators in the knowledge community also act as dominators in business communities, who are recognized as keystones in the innovation ecosystem. Moreover, there two knowledge-dominators that act as niche players in business communities. The roles of the rest of the 210 knowledge-dominators in business communities involve 143 commodity players and 63 pure buyers. Besides, the dominators in the same knowledge community scatter in multiple business communities, which means that these firms have quite different partners in knowledge and business fields.

\section{Discussion}

The application of MIEM provides a holistic view of the multi-layered innovation ecosystem of Ningbo's CNC machine tool industry. Both densities of the whole networks in knowledge and business ecosystems are low, and the community structure in the knowledge 


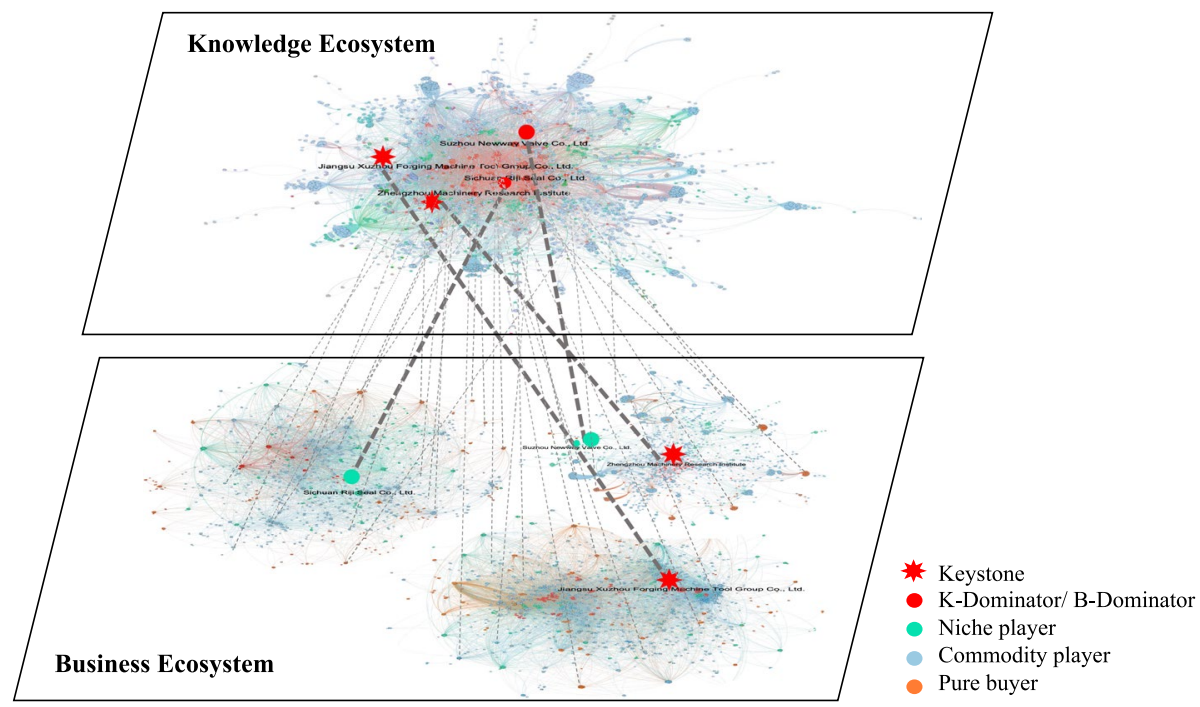

Fig.13 A close-up of strategic roles in communities across layers

network is stronger than that in the business network. What is more, from the linkages across layers, we can see that the overlap of firms between knowledge and business ecosystem are only at a small portion. This phenomenon comports with the notion that the knowledge ecosystem and business ecosystem are two separate worlds (Clarysse et al. 2014; Oh et al. 2016).

Further, we probe into the innovation communities in the innovation ecosystem. From community analysis, we find that the similarity of communities between knowledge ecosystem and business ecosystem is very low, which indicates that firms have different partners in technological collaborations and business transactions. It verifies the notion that there seems to be a disconnection between the knowledge ecosystem and business ecosystem(Clarysse et al. 2014).

Moreover, we recognize players' strategic roles in communities, which can help to examine the balances of "species" in an innovation ecosystem, as well as provide decision support for a firm's future strategy. We noticed that there are more dominators in the communities of knowledge ecosystem, while there are more niche players in the communities of the business ecosystem. It implies that core players in knowledge ecosystems tend to have diversified technical domains, while core players in business ecosystems tend to be more focused on a specific segment. In addition, keystones that have dominant power in both sub-ecosystems are very rare. This again confirms observations from earlier studies that research economy and commercial economy are two separated worlds (Clarysse et al. 2014; Xu et al. 2018).

In summary, applying the MIEM analysis, we observe significant divide between the knowledge ecosystem and the business ecosystem in Ningbo's CNC machine tool industry, which invokes a call for more efforts to enhance the interactions between knowledge and business. 


\section{Conclusions}

This paper conceptualizes an innovation ecosystem as a complex, dynamic system that includes knowledge and business sub-ecosystems, and proposes a multi-layered framework for innovation ecosystem mapping based on multi-source heterogeneous data. In particular, Newman topological clustering is used to detect communities in an ecosystem. Based on this framework, a case study of Ningbo's CNC machine tool industry was conducted for demonstration.

The contributions of this research are as follows:

First, this paper proposes the framework of MIEM to explore both knowledge and business ecosystems, which provides a holistic view of a multi-layered innovation ecosystem involving knowledge creation and business value capture. Multi-source heterogeneous data, including patent data and VAT invoice data, are used to map an ecosystem. This multi-layered framework examines the homogeneity and heterogeneity between knowledge and business ecosystems, which helps to fill in the research gap of innovation ecosystem by bridging the research economy and commercial economy.

Second, this paper sheds light on network community analysis of an innovation ecosystem at the meso level. Network communities can significantly impact firms' innovation activities, which is also essential to promote the evolution of the innovation ecosystem. Newman topological clustering is applied to identify communities, and a strategic-role matrix is used to analyze the roles in communities. These methods enable an in-depth analysis of innovation ecosystems at the meso level. Thus, this research complements existing ecosystem mapping studies that involve either whole-network analysis at the macro-level or ego-network analysis at the micro-level.

Third, this paper provides managerial implications from a case study of Ningbo's CNC machine tool industry, based on MIEM. The results show that there is also a chasm between knowledge and business ecosystems in the real world. This provides insights for policymakers and industrialists to promote the development of the CNC machine tool industry with further efforts to enhance the interactions between knowledge and business.

There are some limitations of this paper. First, due to data availability, this paper only links the same players between layers to examine the interaction between knowledge and business ecosystems. Future research can use other methods to establish the linkages, such as linking a player in a knowledge ecosystem to a player in a business ecosystem if they collaborate on technology transfer and commercialization or have an R\&D outsourcing relationship. Second, even after topological clustering, the community is still large, and future research can perform secondary-level clustering to improve the accuracy of analysis. Third, the knowledge ecosystem can further be divided into science ecosystem and technology ecosystem (Xu et al. 2018), while this paper focuses only on the technology ecosystem. A scientific layer could be added to the multi-layered framework of ecosystem mapping in future research. Finally, in the case of the CNC machine tool industry, we only focus on the inter-firm relationship of cooperation. Future research could extend to other complex relationships in innovation ecosystems, such as competition and complementation.

Acknowledgements This research is supported by the National Natural Science Foundation of China (Grant Numbers: 71872019, 71974107, 91646102, L1924062, L1824040, L1924058, L1824039, L1724034), Beijing Natural Science Foundation (Grant Number: 9182013), Beijing Social Science Foundation (Grant Number: 17GLC058), the Fundamental Research Funds for the Central Universities (Grant Number: 2018XKJC04), and the MOE (Ministry of Education in China) Project of Humanities and Social Sciences (Grant Number: 16JDGC011), the CAE Advisory Project "Research on the strategy of Manufacturing Power towards 2035" (Grant Number: 2019-ZD-9), the National Science and Technology Major Project "High-end 
Numerical Control and Fundamental Manufacturing Equipment" (Grant Number: 2016ZX04005002), the Chinese Academy of Engineering's China Knowledge Centre for Engineering Sciences an Technology Project (Grant Numbers: CKCEST-2020-2-5, CKCEST-2019-2-13, CKCEST-2018-1-13, CKCEST-2017-1-10, CKCEST-2015-4-2), the UK-China Industry Academia Partnership Programme (UK-CIAPP\260), as well as the Volvo-supported Green Economy and Sustainable Development Tsinghua University (20153000181). Also, the authors would like to thank Fang Dong and Jiao Feng for their technical support in this research.

Open Access This article is licensed under a Creative Commons Attribution 4.0 International License, which permits use, sharing, adaptation, distribution and reproduction in any medium or format, as long as you give appropriate credit to the original author(s) and the source, provide a link to the Creative Commons licence, and indicate if changes were made. The images or other third party material in this article are included in the article's Creative Commons licence, unless indicated otherwise in a credit line to the material. If material is not included in the article's Creative Commons licence and your intended use is not permitted by statutory regulation or exceeds the permitted use, you will need to obtain permission directly from the copyright holder. To view a copy of this licence, visit http://creativecommons.org/licenses/by/4.0/.

\section{Appendix 1}

See Table 3.

Table 3 Commodity codes of the CNC machine tool industry Characteristics

\begin{tabular}{lll}
\hline Industry chain & Commodity code & Description \\
\hline Components and parts & 1090109 & Machine tool accessories and auxiliary devices \\
& 1090119 & Valves and faucets \\
& 1090120 & Hydraulic components and devices \\
& 1090121 & Pneumatic components and devices \\
& 1090123 & Bearings and parts \\
& 1090124 & Gears, drive shafts and drive components \\
Numerical control system & 1090125 & Gaskets and bonding pads \\
Complete machine & 109010804 & CNC system \\
& 1090105 & Metal cutting machine \\
& 1090107 & Metal forming machine \\
& 109010801 & Metal non-cutting and non-forming processing equipment \\
& 109010802 & Machining centre (all CNC machine tools) \\
& 109010803 & CNC metal cutting machine \\
& & CNC metal forming machine \\
\hline
\end{tabular}

\section{Appendix 2}

See Table 4. 


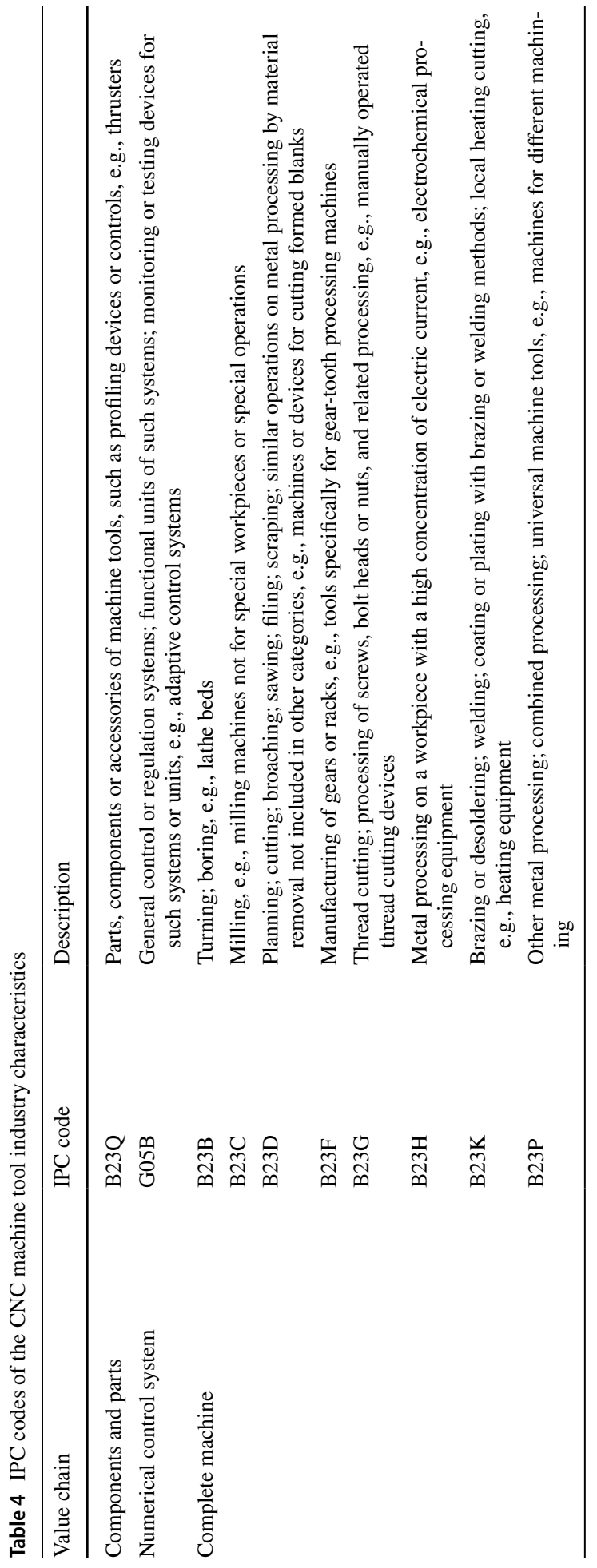




\section{References}

Adner, R. (2017). Ecosystem as structure: An actionable construct for strategy. Journal of Management, 43(1), 39-58.

Adner, R., \& Kapoor, R. (2010). Value creation in innovation ecosystems: how the structure of technological interdependence affects firm performance in new technology generations. Strategic Management Journal, 31(3), 306-333.

Ahuja, G. (2000). Collaboration networks, structural holes, and innovation: A longitudinal study. Administrative Science Quarterly, 45(3), 425-455.

Ardito, L., D’Adda, D., \& Petruzzelli, A. M. (2018). Mapping innovation dynamics in the internet of things domain: Evidence from patent analysis. Technological Forecasting Social Change, 136, 317-330.

Basole, R. C. (2009). Visualization of interfirm relations in a converging mobile ecosystem. Journal of Information Technology, 24(2), 144-159.

Basole, R. C. (2016). Topological analysis and visualization of interfirm collaboration networks in the electronics industry. Decision Support Systems, 83, 22-31.

Battistella, C., Colucci, K., De Toni, A. F., \& Nonino, F. (2013). Methodology of business ecosystems network analysis: A case study in Telecom Italia Future Centre. Technological Forecasting and Social Change, 80(6), 1194-1210.

Bell, G. G. (2005). Clusters, networks, and firm innovativeness. Strategic Management Journal, 26(3), 287-295.

Binz, C., Truffer, B., \& Coenen, L. (2014). Why space matters in technological innovation systemsMapping global knowledge dynamics of membrane bioreactor technology. Research Policy, 43(1), $138-155$.

Clarysse, B., Wright, M., Bruneel, J., \& Mahajan, A. (2014). Creating value in ecosystems: Crossing the chasm between knowledge and business ecosystems. Research Policy, 43(7), 1164-1176.

Danon, L., Diaz-Guilera, A., Duch, J., \& Arenas, A. (2005). Comparing community structure identification. Journal of Statistical Mechanics: Theory and Experiment, $2005(09)$, P09008.

Fiegenbaum, A., \& Thomas, H. (1990). Strategic groups and performance: the US insurance industry, 1970-84. Strategic Management Journal, 11(3), 197-215.

Freeman, L. C. (1979). Centrality in social networks: conceptual clarification. Social Networks, 1(3), 215-239.

Frenkel, A., \& Maital, S. (2014). Mapping national innovation ecosystems: Foundations for policy consensus. Cheltenham: Edward Elgar Publishing.

Hannah, D. P., \& Eisenhardt, K. M. (2018). How firms navigate cooperation and competition in nascent ecosystems. Strategic Management Journal, 39(12), 3163-3192.

Iansiti, M., \& Levien, R. (2004). Strategy as ecology. Harvard Business Review, 34(3), 68-78.

Ibáñez, A., Larrañaga, P., \& Bielza, C. (2013). Cluster methods for assessing research performance: exploring Spanish computer science. Scientometrics, 97(3), 571-600.

Isckia, T. (2009). Amazon's evolving ecosystem: A cyber-bookstore and application service provider. Canadian Journal of Administrative Sciences/Revue Canadienne des Sciences de l'Administration, 26(4), 332-343.

Jackson, D. J. (2011). What is an innovation ecosystem. National Science Foundation, 1-11.

Kernighan, B. W., \& Lin, S. (1970). An efficient heuristic procedure for partitioning graphs. The Bell Systems Technical Journal, 49(2), 291-307.

Kim, B., Gazzola, G., Lee, J.-M., Kim, D., Kim, K., \& Jeong, M. K. (2014). Inter-cluster connectivity analysis for technology opportunity discovery. Scientometrics, 98(3), 1811-1825.

Kim, Y. G., Suh, J. H., \& Sang, C. P. (2008). Visualization of Patent Analysis for Emerging Technology. New York: Pergamon Press.

Kohonen, T. (1982). Self-organized formation of topologically correct feature maps. Biological Cybernetics, 43(1), 59-69.

Kong, D., Zhou, Y., Liu, Y., \& Xue, L. (2017). Using the data mining method to assess the innovation gap: A case of industrial robotics in a catching-up country. Technological Forecasting and Social Change, 119, 80-97.

Lee, S., \& Kim, W. (2017). The knowledge network dynamics in a mobile ecosystem: a patent citation analysis. Scientometrics, 111(2), 717-742.

Li, Y.-R. (2009). The technological roadmap of Cisco's business ecosystem. Technovation, 29(5), 379-386.

Liu, Y., Zhou, Y., Liu, X., Dong, F., Wang, C., \& Wang, Z. (2019). Wasserstein GAN-based small-sample augmentation for new-generation artificial intelligence: a case study of cancer-staging data in biology. Engineering, 5(1), 156-163.

Maimon, O., \& Rokach, L. (2010). The data mining and knowledge discovery handbook. Boston: Springer. 
Moore, J. F. (1993). Predators and prey: A new ecology of competition. Harvard Business Review, 71(3), 75-86.

Newman, M. E. (2004). Fast algorithm for detecting community structure in networks. Physical Review E, 69(6), 066133.

Oh, D. S., Phillips, F., Park, S., \& Lee, E. (2016). Innovation ecosystems: A critical examination. Technovation, 54, 1-6.

Panetti, E., Parmentola, A., Ferretti, M., \& Reynolds, E. B. (2019). Exploring the relational dimension in a smart innovation ecosystem: a comprehensive framework to define the network structure and the network portfolio. The Journal of Technology Transfer, 1-22.

Phaal, R., Farrukh, C. J., \& Probert, D. (2010). Roadmapping for strategy and innovation: aligning technology and markets in a dynamic world. Institute for Manufacturing.

Porac, J. F., Thomas, H., Wilson, F., Paton, D., \& Kanfer, A. (1995). Rivalry and the industry model of Scottish knitwear producers. Administrative Science Quarterly, 40(2), 203-227.

Porter, M. E. (1998). Clusters and the new economics of competition. Boston: Harvard Business Review.

Pouder, R., \& St. John, C. H. (1996). Hot spots and blind spots: Geographical clusters of firms and innovation. Academy of Management Review, 21(4), 1192-1225.

Rong, K., Hu, G., Lin, Y., Shi, Y., \& Guo, L. (2015). Understanding business ecosystem using a 6C framework in Internet-of-Things-based sectors. International Journal of Production Economics, 159, 41-55.

Salavisa, I., Sousa, C., \& Fontes, M. (2012). Topologies of innovation networks in knowledge-intensive sectors: Sectoral differences in the access to knowledge and complementary assets through formal and informal ties. Technovation, 32(6), 380-399.

Schilling, M. A., \& Phelps, C. C. (2007). Interfirm collaboration networks: The impact of large-scale network structure on firm innovation. Management Science, 53(7), 1113-1126.

Shibata, N., Kajikawa, Y., Takeda, Y., \& Matsushima, K. (2008). Detecting emerging research fronts based on topological measures in citation networks of scientific publications. Technovation, 28(11), 758-775.

Shipilov, A., \& Gawer, A. (2020). Integrating Research on Interorganizational Networks and Ecosystems. Academy of Management Annals, 14(1), 92-121.

Skute, I., Zalewska-Kurek, K., Hatak, I., \& de Weerd-Nederhof, P. (2019). Mapping the field: a bibliometric analysis of the literature on university-industry collaborations. Journal of Technology Transfer, 44(3), 916-947.

Sytch, M., \& Tatarynowicz, A. (2014). Exploring the locus of invention: The dynamics of network communities and firms' invention productivity. Academy of Management Journal, 57(1), 249-279.

Sytch, M., Tatarynowicz, A., \& Gulati, R. (2012). Toward a theory of extended contact: The incentives and opportunities for bridging across network communities. Organization Science, 23(6), 1658-1681.

Wang, B., Liu, Y., Zhou, Y., \& Wen, Z. (2018). Emerging nanogenerator technology in China: A review and forecast using integrating bibliometrics, patent analysis and technology roadmapping methods. Nano energy, 46, 322-330.

Xu, G., Wu, Y., Minshall, T., \& Zhou, Y. (2018). Exploring innovation ecosystems across science, technology, and business: A case of 3D printing in China. Technological Forecasting and Social Change, 136, 208-221.

Zaheer, A., \& Bell, G. G. (2005). Benefiting from network position: firm capabilities, structural holes, and performance. Strategic Management Journal, 26(9), 809-825.

Zaheer, A., Gözübüyük, R., \& Milanov, H. (2010). It's the connections: The network perspective in interorganizational research. Academy of Management Perspectives, 24(1), 62-77.

Zhou, Y., Dong, F., Kong, D., \& Liu, Y. (2019a). Unfolding the convergence process of scientific knowledge for the early identification of emerging technologies. Technological Forecasting and Social Change, $144,205-220$.

Zhou, Y., Dong, F., Liu, Y., Li, Z., Du, J., \& Zhang, L. (2020). Forecasting emerging technologies using data augmentation and deep learning. Scientometrics, 123, 1-29.

Zhou, Y., Li, X., Lema, R., \& Urban, F. (2016). Comparing the knowledge bases of wind turbine firms in Asia and Europe: Patent trajectories, networks, and globalisation. Science and Public Policy, 43(4), 476-491.

Zhou, Y., Lin, H., Liu, Y., \& Ding, W. (2019b). A novel method to identify emerging technologies using a semi-supervised topic clustering model: a case of 3D printing industry. Scientometrics, 120(1), $167-185$.

Zhou, Y., Zang, J., Miao, Z., \& Minshall, T. (2019c). Upgrading pathways of intelligent manufacturing in China: Transitioning across technological paradigms. Engineering, 5(4), 691-701. 